ORIGINAL ARTICLE

\title{
Rapidly progressive coal workers' pneumoconiosis in the United States: geographic clustering and other factors
}

\author{
V C dos S Antao, E L Petsonk, L Z Sokolow, A L Wolfe, G A Pinheiro, J M Hale, M D Atffield
}

Occup Environ Med 2005;62:670-674. doi: 10.1136/oem.2004.019679

See end of article for authors' affiliations

Correspondence to: $\operatorname{Dr} \vee$ Antao, Division of Respiratory Disease Studies, National Institute for Occupational Safety and Health, Centers for Disease Control and Prevention, 1095 Willowdale Road, MS 2800, Morgantown, WV 26505, USÄ; VAntao@ cdc.gov

Accepted 8 March 2005

\begin{abstract}
Background: Despite significant progress made in reducing dust exposures in underground coal miners in the United States, severe cases of coal workers' pneumoconiosis (CWP), including progressive massive fibrosis (PMF), continue to occur among coal miners.

Aims: To identify US miners with rapidly progressive CWP and to describe their geographic distribution and associated risk factors.

Methods: Radiographic evidence of disease progression was evaluated for underground coal miners examined through US federal chest radiograph surveillance programmes from 1996 to 2002. A case of rapidly progressive CWP was defined as the development of PMF and/or an increase in small opacity profusion greater than one subcategory over five years. County based prevalences were derived for both CWP and rapidly progressive cases.

Results: A total of 886 cases of CWP were identified among 29521 miners examined from 1996 to 2002. Among the subset of 783 miners with CWP for whom progression could be evaluated, 277 (35.4\%) were cases of rapidly progressive CWP, including 41 with PMF. Miners with rapidly progressive CWP were younger than miners without rapid progression, were more likely to have worked in smaller mines $(<50$ employees), and also reported longer mean tenure in jobs involving work at the face of the mine (in contrast to other underground mining jobs), but did not differ with respect to mean underground tenure. There was a clear tendency for the proportion of cases of rapidly progressive CWP to be higher in eastern Kentucky, and western Virginia.

Conclusions: Cases of rapidly progressive CWP can be regarded as sentinel health events, indicating inadequate prevention measures in specific regions. Such events should prompt investigations to identify causal factors and initiate appropriate additional measures to prevent further disease.
\end{abstract}

progressive cases of CWP, and to investigate their geographic distribution and certain other factors that may contribute to disease causation. The results provide evidence of geographic clustering, and suggest the need for further investigation and strengthening of public health measures.

\section{METHODS}

According to CWXSP regulations, every miner who works at an underground coal mine in the USA is eligible to have a chest radiograph once every five years at an NIOSH approved facility. Radiographs taken under the provisions of this programme, as well as those which were taken through the MSHA Miners' Choice Program, are classified for the presence and severity of abnormalities consistent with pneumoconiosis, according to the International Labour Office (ILO) Classification of Radiographs of Pneumoconiosis. ${ }^{6}$ A final determination of the classification of each radiograph is made using a standardised procedure, and requires agreement between at least two NIOSH certified readers. ${ }^{4}$ The results of the readings are stored in a database along with additional information provided by the miner, including a coal mining work history.

For this report, we used the computerised data to evaluate the prevalence of CWP among all underground miners who had been examined in the CWXSP and the MSHA Miners' Choice Program from 1996 to 2002. Disease progression was also assessed for those miners who had been evaluated

Abbreviations: CWP, coal workers' pneumoconiosis; CWXSP, Coal Workers' X-ray Surveillance Program; ILO, International Labour Office; $\mathrm{NIOSH}$, National Institute for Occupational Safety and Health; PMF, progressive massive fibrosis occur among relatively young US coal miners. This report describes initial efforts to systematically identify rapidly ray evidence of CWP, representing a substantial reduction miners showed disease ${ }^{4}$ Amon CWP varied by state from 0 to $9.6 \%{ }^{4}$ Despite excellent overall progress in reducing dust exposures, ${ }^{5}$ severe cases of CWP, including progressive massive fibrosis (PMF), continue to 


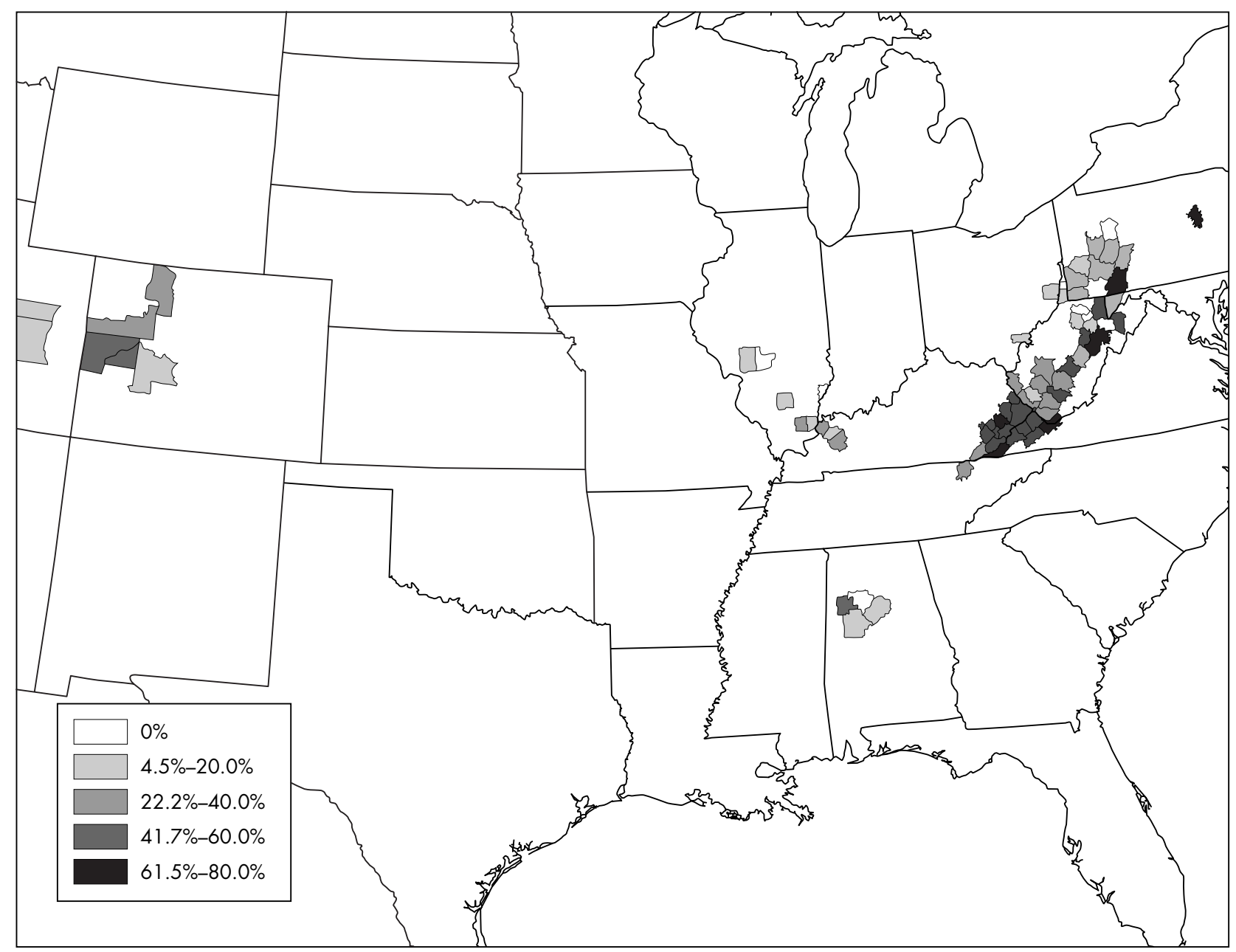

Figure 1 Proportion of evaluated miners with rapidly progressive coal workers' pneumoconiosis by county (not shown are counties with fewer than five miners evaluated).

during that same period, had at least two examinations (including pre-1996 films, if available), and whose most recent radiograph showed at least category $1 / 1$ pneumoconiosis.

A case of rapidly progressive CWP was defined radiographically as an increase in the small opacity profusion by the equivalent of more than one ILO subcategory over five years after 1985, and/or the development or progression of PMF after 1985. To reduce the likelihood of false positive cases, if all of a miner's previous radiographs were classified as normal, the classification of rapid progression was limited to cases in which the most recent chest radiograph showed a final profusion determination of $\geqslant 1 / 2$. Determining rapid progression only after 1985 allowed for more than 10 years latency following the reduction in respirable dust levels mandated by the 1969 Act. Progression of disease after 1985 would be expected to primarily reflect the regulated coal mine conditions and dust concentrations from 1970, although PMF may develop after dust exposure ceases.

Rapid progression was determined for this report using the historical final $x$ ray determinations recorded in the database of the CWXSP. The reliability of the case definition based on these older readings was assessed by retrieving all films stored in the CWXSP archives for a subset of 211 randomly selected participating miners. Radiographic progression was evaluated for miners in this subset, with side by side readings, by two experts reading together, who were blinded to the previous readings, using the case criteria described above. Rapid progression case classifications from the recent readings were compared to the case status based on the historical readings for the sample of 211 miners.

The county based prevalence of CWP was calculated as the number of miners in a county with radiographic evidence of CWP (final profusion determination $\geqslant 1 / 0$ ) divided by the total number of miners at all coal mines in the county who had participated in the CWXSP during the designated time period. The proportion of rapidly progressive CWP was calculated as the number of cases of rapid progression in each county divided by the total number of miners in the county with CWP for whom progression was assessed. Cases were assigned to the county of the mine at which the most recent chest radiograph was taken, without considering the location of previous coal mine employment, if any. Student's $t$ test was used to estimate the differences between means, and odds ratio were calculated directly. The SAS statistical software package version 8.02 (SAS Institute, Cary, NC) was used for all the analyses. ArcView GIS version 8.3 (Environmental Systems Research Institutes, Redlands, CA) was used to map the geographic distribution of rapidly progressive cases of CWP.

\section{RESULTS}

A total of 886 cases of CWP were identified among the 29521 miners evaluated in the period 1996-2002, giving an overall crude prevalence of 3\%. Among the subset of 783 miners with CWP, who had a least two radiographs permitting 
Table 1 Proportion of evaluated miners with rapidly progressive coal workers' pneumoconiosis by county (not listed are counties with fewer than five miners evaluated and less than $40 \%$ of evaluated miners with rapid progression)

\begin{tabular}{|c|c|c|c|c|c|}
\hline County (state) & $\begin{array}{l}\text { Miners examined } \\
(1996-2002) \\
\text { (n) }\end{array}$ & $\begin{array}{l}\text { Prevalence of CWP* } \\
(\%)\end{array}$ & $\begin{array}{l}\text { Miners evaluated } \dagger \\
\text { (n) }\end{array}$ & $\begin{array}{l}\text { Miners with rapid } \\
\text { progression } \\
\text { (n) }\end{array}$ & $\begin{array}{l}\text { Proportion of evaluated } \\
\text { miners with rapid } \\
\text { progression } \\
\text { (\%) }\end{array}$ \\
\hline Columbia (PA) & 82 & 6.5 & 5 & 4 & 80.0 \\
\hline Lee (VA) & 142 & 3.5 & 5 & 4 & 80.0 \\
\hline Knott (KY) & 289 & 4.2 & 9 & 6 & 66.7 \\
\hline Somerset (PA) & 281 & 3.2 & 14 & 9 & 64.3 \\
\hline Randolph (WV) & 17 & 17.6 & 8 & 5 & 62.5 \\
\hline Tazewell (VA) & 121 & 9.9 & 26 & 16 & 61.5 \\
\hline Leslie (KY) & 134 & 4.5 & 5 & 3 & 60.0 \\
\hline Martin (KY) & 141 & 5.0 & 10 & 6 & 60.0 \\
\hline Wise (VA) & 1095 & 6.0 & 63 & 37 & 58.7 \\
\hline Grant (WV) & 42 & 14.3 & 7 & 4 & 57.1 \\
\hline Pike (KY) & 748 & 6.8 & 73 & 39 & 53.4 \\
\hline Dickenson (VA) & 292 & 10.3 & 31 & 16 & 51.6 \\
\hline Floyd (KY) & 68 & 5.9 & 6 & 3 & 50.0 \\
\hline Preston (WV) & 199 & 8.0 & 16 & 8 & 50.0 \\
\hline Fayette (AL) & 304 & 2.6 & 8 & 4 & 50.0 \\
\hline Buchanan (VA) & 736 & 8.6 & 122 & 60 & 49.2 \\
\hline Russell (VA) & 99 & 1.0 & 13 & 6 & 46.2 \\
\hline Upshur (WV) & 170 & 5.3 & 13 & 6 & 46.2 \\
\hline Delta (CO) & 370 & 0.8 & 11 & 5 & 45.5 \\
\hline Nicholas (WV) & 140 & 3.6 & 11 & 5 & 45.5 \\
\hline Perry (KY) & 223 & 4.9 & 9 & 4 & 44.4 \\
\hline Letcher (KY) & 504 & 3.6 & 23 & 10 & 43.5 \\
\hline Raleigh (WV) & 302 & 10.9 & 51 & 22 & 43.1 \\
\hline Mesa (CO) & 53 & 5.7 & 7 & 3 & 42.9 \\
\hline Harlan (KY) & 400 & 3.3 & 24 & 10 & 41.7 \\
\hline
\end{tabular}

*Miners with small opacity profusion $\geqslant 1 / 0$, divided by the estimated average number of miners employed during the evaluation period, by county. †Miners examined in 1996-2002 who had at least two examinations (including pre-1996).

progression to be evaluated, $277(35.4 \%)$ were cases of rapidly progressive CWP. PMF was evident in 41 (14.8\%) cases of rapidly progressive CWP (16 stage A, 20 stage B, and 5 stage C). Eight cases showed progression of one subcategory over $\leqslant 5$ years, 156 cases had progression equivalent to $2-3$ subcategories over a five year period, and 72 cases progressed the equivalent of more than three subcategories over a five year period. Rounded opacities were the primary shape/size in $73 \%$ of the rapidly progressive cases $(p=13 \%$; $q=47 \% ; r=13 \%$ ), compared to $50 \%$ in the non-rapidly progressive cases $(\mathrm{p}=13 \% ; \mathrm{q}=33 \% ; \mathrm{r}=4 \%)$.

As one actual example, we describe the case of a 22 year old man from eastern Kentucky who started underground coal mining in 1974. A pre-employment radiograph was normal. He initially operated a shuttle car, but spent most of the next 18 years operating a continuous mining machine. In 1992, his chest $x$ ray indicated the presence of CWP, with a profusion of small opacities of $1 / 2$. By 2000, the small opacities had progressed to a profusion of $2 / 1$, and large opacities of PMF, stage B were present.

Overall, the 277 miners with rapidly progressive CWP were somewhat younger than the remaining miners evaluated (mean age (SD) 48 (6) versus 51 (6) years old; $p<0.00001$ ), but were not different with respect to mean tenure (27 (6) versus 26 ( 8 ) years; $p=0.17$ ). Rapidly progressive cases were more likely to have worked in smaller mines (with $<50$ employees) than in larger mines (OR $1.55,95 \%$ CI 1.2 to 2.0; $\mathrm{p}<0.001)$. Work histories, including mining job location and title, were available for 762 of the 783 miners evaluated. Rapidly progressive CWP cases reported longer mean tenure in jobs involving work at the face of the mine (in contrast to other underground mining jobs), compared to miners without rapid progression (19 (10) versus 17 (10) years; $\mathrm{p}<0.01)$.

The miners for whom progression was assessed had worked in 14 different states and 137 different counties. Table 1 lists the counties $(\mathrm{n}=25)$ in which progression was evaluated for at least five miners with CWP, and at least $40 \%$ of evaluated miners were rapidly progressive cases. Figure 1 shows the geographic distribution of rapidly progressive cases for all counties in which at least five miners were evaluated.

The correlation between the prevalence of rapidly progressive CWP and the overall prevalence of CWP by county $(\mathrm{r}=0.34 ; \mathrm{p}<0.01)$ is shown in fig 2 . One of the counties showed a high prevalence of CWP, but very few cases of rapid progression. In contrast, several counties had a relatively low prevalence of CWP, but a high proportion of rapidly progressive CWP cases.

Utilising the recent determinations of rapid progression among the random subset of 211 miners as a "gold standard", rapid progression as defined based on the older readings appeared to be fairly reliable, showing sensitivity of $87.3 \%$, specificity of $92.6 \%$, predictive value positive of $83.3 \%$, and predictive value negative of $94.5 \%$.

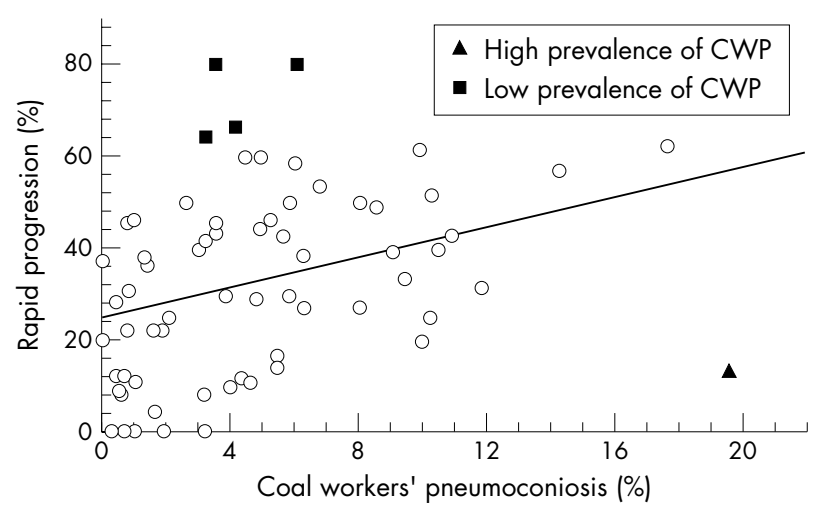

Figure 2 Scatter plot showing the correlation between prevalence of rapid progression and overall prevalence of coal workers' pneumoconiosis in the USA, by county. 


\section{Main messages}

- Although the prevalence of CWP is declining in the USA, severe and rapidly progressive cases of the disease continue to occur among young miners.

- Cases of rapidly progressive CWP appear to be clustered in eastern Kentucky and western Virginia.

\section{DISCUSSION}

Based on data obtained through the CWXSP, the prevalence of pneumoconiosis has declined markedly among working underground US coal miners. This decline is an expected outcome following the passage of the Coal Mine Health and Safety Act of 1969, and enforcement of the Act's dust exposure limits. However, recent reports have indicated that pneumoconiosis is still occurring among some young miners, ${ }^{4}$ advanced cases are likely to result in respiratory disability and premature death. ${ }^{7}$ In order to investigate causes resulting in the persistence of a preventable disease, we sought to identify cases of rapidly progressive CWP, and evaluate their geographic distribution and other associated factors. The results of our study do suggest geographic clustering of rapidly progressive cases of CWP, with a clear tendency for the proportion of CWP cases that are rapidly progressive to be higher in eastern Kentucky, and western Virginia (fig 1). In several coal mining counties, over two thirds of working miners with pneumoconiosis showed rapid progression (table 1). Rapid progression was also significantly associated with work in smaller mines (less than 50 employees) and with longer tenure in jobs at the face of the mine. Of particular concern, miners with rapidly progressive CWP were significantly younger than other miners with CWP, strongly implicating recent mining conditions.

The high rates of progression observed in these coal miners are quite unexpected. Two decades ago, Althouse et al showed low rates of progression among 1834 miners in the USA and no new cases of PMF were observed after approximately 10 years of underground work. ${ }^{8}$ Recently, the risks of developing CWP category 2 or PMF over a working lifetime of 40 years have been estimated to be around $2 \%$. ${ }^{9}$ These results exceed the predictions for progression formulated by Jacobsen, ${ }^{10}$ considering that the mandated dust sampling indicates that most US miners have been exposed to environments below the $2 \mathrm{mg} / \mathrm{m}^{3}$ limit for respirable coal mine dust.

Do the data suggest explanations for these unexpected findings? The association of rapid progression with work in smaller mines and at the face of the mines is not surprising. Previous studies have reported that respirable coal mine dust concentrations in smaller mines are on average higher than in larger mines. ${ }^{21}$ Similarly, dust exposure at the coal face is typically greater than elsewhere in the mine, and miners cutting coal at the mine face have been previously shown to experience more rapid progression of CWP. ${ }^{12}$ Thus, some of the observed rapid disease progression can be explained by miners working in higher dust environments, in smaller mines and during face work. However, additional explanations must be sought.

The cases of rapidly progressive CWP appear to cluster along the eastern edge of the Appalachian coal field. Amandus et al previously noted that miners in West Virginia and Pennsylvania progressed more rapidly than did miners in the western parts of the country, which showed negligible progression. ${ }^{13}$ Coal rank, a measure of the age and hardness of coal, may in part explain this clustering. Rank tends to decline from east to west in the USA, and miners in higher rank coal seams are at greater risk of contracting CWP,

\section{Policy implications}

- Rapidly progressive cases of CWP can be regarded as sentinel health events, indicating inadequate prevention measures in specific regions.

- Targeted investigations should take place to identify causal factors and to prompt appropriate strengthening of disease prevention measures.

even after accounting for respirable dust exposure. ${ }^{14}$ Mining anthracite (coal of the highest rank) is associated with a "hot spot" of rapid progression located in eastern Pennsylvania (fig l). Again, coal rank does not appear to fully explain the observed geographic distribution of rapidly progressive cases. Differences in mining technique, approaches to dust control, or enforcement of permissible exposure limits may also play a role. Other geological conditions, leading to excessive exposure to quartz, have been implicated in higher rates of rapid progression as well. ${ }^{12}$

The presence of outliers in the correlation between rapid progression and CWP prevalence suggests that some counties may have a population of older miners, with stable or slowly progressive disease, while others may represent recent high exposures, or other undefined factors, that may be associated with rapid progressive cases.

These results are subject to a number of limitations. Interreader variability ${ }^{13}{ }^{15}{ }^{16}$ might have affected the ascertainment of rapidly progressive cases of CWP because the evaluation of progression was based on independent readings by different readers made at the time each $x$ ray was taken. However, good reliability of the case definition was shown through a review of a subset of films from 211 miners. Moreover, $97 \%$ of the rapidly progressive cases were determined based on an increase of at least two subcategories, which reduces the likelihood of simple inter-reader variability affecting the determination of progression. Participation rates in the CWXSP have been low (about $31 \%$ of miners employed at underground coal mines ${ }^{4}$ ), which could have introduced selection biases and limited the ability to generalise the results on prevalence. However, the clear association of rapidly progressive cases of CWP with previously identified hazardous environments (for example, at smaller mines and the coal face) supports the validity of the findings. ${ }^{14}$ Finally, mis-estimation of rapid progression rates for some counties might have resulted from smaller numbers of miners employed, low participation, migration between counties, and withdrawal from underground mining due to retirement or disability.

Radiographic progression of CWP is considered a useful index in studies of the association between dust exposure and disease, and may be a better epidemiological tool than the simple measurement of disease prevalence. ${ }^{17}$ In spite of the excellent progress in reducing the occurrence of CWP, the current study results suggest that cases of rapidly progressive CWP can be regarded as sentinel health events, indicating inadequate prevention measures in specific regions. Such events should prompt investigations to identify preventable causes and appropriate additional actions to prevent further disease. The 1969 Act provides the miner whose radiograph shows evidence of CWP with the right to request a transfer to a job where the dust concentration is not more than $1 \mathrm{mg} / \mathrm{m}^{3}$ of air, with no loss of regular pay. ${ }^{3}$ Nevertheless, only a small proportion of eligible miners exercise this right. ${ }^{15}$ The results of this study and related efforts should be used to increase awareness of the risk of rapid progression of CWP, acknowledging that disease can progress even after transfer/ 
retirement, but it is less likely to occur if the dust exposure has been reduced. The continued incidence of CWP, and particularly rapidly progressive CWP, indicates the need for particular vigilance with regards to enforcement of the current dust limits in smaller mines and in specific regions, and suggests that additional measures to control exposures may be needed to enhance the protection of miners. In particular, as recommended in the NIOSH Criteria document, ${ }^{14}$ reduction of the coal mine dust exposure limit, especially in high rank coal mining areas is desirable. Widespread application of an accurate and practical continuous personal dust monitor may provide coal miners improved assurance that respirable coal mine dust exposures are uniformly within regulated limits. ${ }^{18}$

\section{ACKNOWLEDGEMENTS}

The authors would like to thank the staff from the NIOSH CWXSP (Lea Pyles, Jennifer Keller, Polly Van Gilder, and James Lawson) for supplying and retrieving the data for this report.

\section{Authors' affiliations}

V C dos S Antao, E L Petsonk, A L Wolfe, G A Pinheiro, J M Hale,

M D Atffield, Division of Respiratory Disease Studies, National Institute for Occupational Safety and Health, Centers for Disease Control and Prevention, Morgantown, WV, USA

L Z Sokolow, Biolntelligence Center, National Center for Public Health Informatics, Centers for Disease Control and Prevention, Atlanta, GA, USA

Competing interests: none declared

\section{REFERENCES}

1 Atffield MD, Morring K. An investigation into the relationship between coal workers' pneumoconiosis and dust exposure in U.S. coal miners. Am Ind Hyg Assoc J 1992;53:486-92.

2 Kenny LC, Hurley F, Warren ND. Estimation of the risk of contracting pneumoconiosis in the UK coal mining industry. Ann Occup Hyg 2002;46(suppl 1):257-60.

3 Federal Coal Mine Health and Safety Act. Public Law no. 91-173 (1969).
4 Centers for Disease Control and Prevention. Pneumoconiosis prevalence among working coal miners examined in federal chest radiograph surveillance programs-United States, 1996-2002. MMWR Morb Mortal Wkly Rep 2003;52:336-40.

5 Parobeck PS, Jankowski RA. Assessment of the respirable dust levels in the nation's underground and surface coal mining operations. Am Ind Hyg Assoc J 1979;40:910-15.

6 International Labour Office. Guidelines for the use of ILO International Classification of Pneumoconiosis. Geneva, Switzerland: International Labour Office, 1980.

7 Kuempel ED, Stayner LT, Atffield MD, et al. Exposure-response analysis of mortality among coal miners in the United States. Am J Ind Med 1995:28:167-84.

8 Althouse R, Attfield M, Kellie S. Use of data from X-ray screening program for coal workers to evaluate effectiveness of $2 \mathrm{mg} / \mathrm{m}^{3}$ coal dust standard. J Occup Med 1986;28:741-5.

9 Soutar CA, Hurley JF, Miller BG, et al. Dust concentrations and respiratory risks in coalminers: key risk estimates from the British Pneumoconiosis Field Research. Occup Environ Med 2004;61:477-81.

10 Jacobsen M. Progression of coal workers' pneumoconiosis in Britain in relation to environmental conditions underground. Proceedings of the Conference on Technical Measures of Dust Prevention and Suppression in Mines. Luxembourg: Commission of the European Communities 1972:77-93.

11 Report of the Statistical Task Team of the Coal Mine Respirable Dust Task Group. Washington, DC: US Department of Labor, Mine Safety and Health Administration, September 1993.

12 Seaton A, Dick JA, Dodgson J, et al. Quartz and pneumoconiosis in coalminers. Lancet 1981;318:1272-5.

13 Amandus HE, Reger RB, Pendergrass EP, et al. The pneumoconioses: methods of measuring progression. Chest 1973;63:736-43.

14 Centers for Disease Control and Prevention. Criteria for a recommended standard. Occupational exposure to respirable coal mine dust. Publication No. 95-106. US Department of Health and Human Service, National Institute for Occupational Safety and Health.

15 Wagner GR, Spieler EA. Is the US Coal Miner Chest X-ray Surveillance Program succeeding in controlling lung disease? Proceedings of the VIlth International Pneumoconioses Conference. Pittsburgh, PA, 1988:803-6.

16 Wagner GR, Attfield MD, Parker JE. Chest radiography in dust-exposed miners: promise and problems, potential and imperfections. Occup Med 1993;8:127-41.

17 Liddell FD, Morgan WK. Methods of assessing serial films of the pneumoconioses: a review. J Soc Occup Med 1978;28:6-15.

18 Volkwein JC, Vinson RP, McWilliams $\sqcup$, et al. Performance of a new personal respirable dust monitor for mine use. DHHS (NIOSH) Publication No. 2004151. US Department of Health and Human Services, Centers for Disease Control and Prevention, National Institute for Occupational Safety and Health, June, 2004. 